\title{
A Intervenção profissional do/ assistente social nas demandas sociojurídicas da Comarca de Marabá (PA)
}

The Professional Intervention of the Social Assistant in the Sociojuridical Demands of the Marabá Comarca (PA)

\author{
Edevaldo da Luz Azevedo * \\ Reinaldo Nobre Pontes **
}

\section{Resumo:}

Este trabalho se apresenta como fruto de uma pesquisa qualitativa voltada a explicitar o processo de intervenção técnica dos/as assistentes sociais do Poder Judiciário paraense no trato das demandas sociojurídicas, com o objetivo de analisar as dimensões ético-políticas e técnico-operativas do exercício profissional em Serviço Social e suas determinações históricas e sociopolíticas, enquanto profissão inserida no campo sociojurídico, a partir de sua operacionalização na Comarca de MarabáPA.

Palavras-Chave: Estado. Serviço social. Poder Judiciário. Demandas sociojurídicas. Exercício profissional.

\begin{abstract}
:
This work is presented as a qualitative research aimed at explaining the process of technical intervention of the social workers of the Judiciary Power in the treatment of sociolegal demands, with the objective of analyzing the ethical-political and technical-operational dimensions of the professional practice in Social Service and its historical and sociopolitical determinations, as a profession inserted in the sociolegal field, starting from its operationalization in the Marabá-PA Region.
\end{abstract}

Keywords: State. Social work. Judiciary. Sociojuridical lawsuits. Professional practice.

\section{Introdução}

O presente trabalho advém de uma inquietação suscitada no processo de intervenção profissional em Serviço Social no âmbito do Poder Judiciário paraense, o que motivou a necessidade de se buscar referências nas literaturas, nos eventos da categoria que implicam em debates e discussões atinentes à pdrática e às temáticas relacionadas ao exercício profissional, e que culminou no exercício do curso de mestrado em Serviço Social, componente do Programa de Pós-Graduação em Serviço Social - PPGSS, da Universidade

\footnotetext{
* Aluno do Programa de Pós-Graduação em Serviço Social da Universidade Federal do Pará, Mestrado Turma 2016. E-mail: ede.azev@gmail.com

** Professor Doutor do Programa de Pós-Graduação em Serviço Social da Universidade Federal do Pará.
} 
Federal do Pará - UFPA, em que se optou abordar a intervenção técnica de assistentes sociais no campo sociojurídico, especialmente no Poder Judiciário, a partir de uma comarca judiciária do interior do estado do Pará.

É válido ressaltar, que o assunto abordado possui característica de originalidade acadêmico-científica em razão de se efetuar previamente, ainda em seu planejamento consolidado no projeto de pesquisa de mestrado, no mês de abril de 2017, investigações bibliográficas em portais eletrônicos de um considerável número de periódicos que abordam temáticas trabalhadas pelo Serviço Social. Assim, observou-se que, ao nível do estado do Pará e no âmbito do Serviço Social, não há trabalho científico-acadêmico que discorra sobre esta mesma temática.

Com isso, o objetivo principal traçado vislumbrou analisar as dimensões éticopolíticas e técnico-operativas da intervenção profissional dos/as assistentes sociais e suas determinações históricas e sociopolíticas no trato das demandas sociojurídicas no Tribunal de Justiça do Estado do Pará, demandas estas vinculadas à Comarca de Marabá. Para se alcançar tal objetivo, foram traçados os seguintes objetivos específicos: Compreender as mediações e determinações da relação entre o Poder Judiciário e o Serviço Social, no âmbito de uma sociedade capitalista e na região amazônica brasileira; assinalar as demandas sociojurídicas que se constituem objeto de intervenção profissional do(a) assistente social; verificar os instrumentais e técnicas utilizados pelos assistentes sociais que os habilitam a efetivar as perícias sociais no âmbito do Poder Judiciário; Identificar as percepções de magistrados em face da intervenção do(a) assistente social na área sociojurídica; averiguar as condições éticas e técnicas do exercício profissional em Serviço Social no ambiente sócioocupacional do campo sociojurídico.

Como método científico-investigativo, optou-se pela utilização do método dialético enquanto diretriz científico-filosófica no desenvolvimento do processo investigativo, por se entender que tal método possibilita uma maior aproximação com a essência do real, dos fenômenos que envolvem o objeto a ser apreendido pela razão, o qual precisa inicialmente ser negado, desconstruído e, mediante o movimento dialético da realidade, ser reconstruído, em que serão identificadas as categorias que determinam esse mesmo objeto.

Ressalta-se que os sujeitos pesquisados envolvidos corresponderam a um total de 07 profissionais que atuam na Comarca de Marabá-PA, sendo 04 assistentes sociais e 03 profissionais do Direito que ocupam o cargo de magistrado, e que aceitaram o convite para 
participarem do trabalho, ficando todos submetidos às entrevistas semi-estruturadas no período acima mencionado, em que o critério para a escolha dos magistrados repousou na condição de estes manterem uma relação interprofissional com as assistentes sociais pesquisadas.

Por se optar pelo aspecto qualitativo como uma das modalidades de pesquisa científico-acadêmica, recorreu-se à técnica de análise de conteúdo referenciado em Bardin (2011) para que as verbalizações dos sujeitos fossem adequadamente interpretadas, buscando-se verificar a representação da comunicação estabelecida a partir dos significados da linguagem adotada pelos sujeitos da pesquisa, e com que frequência esses significados emergiam no processo de interlocução. Concernente à sistematização das evidências empíricas colhidas durante a pesquisa, novamente se fez uso da técnica de análise de conteúdo em Bardin (2011) e, com isso, foram construídos quadros de análise dessas evidências, com recortes de trechos das falas dos sujeitos pesquisados.

Desse modo, ao se identificar as principais categorias no processo investigativo, apresentou-se como resultado a descrição e a observação das demandas sociojurídicas trabalhadas, da prática profissional adotada, do instrumental técnico utilizado, das condições de trabalho em que se desenvolve o exercício profissional e da relação interprofissional vivenciada no ambiente de trabalho dos sujeitos da pesquisa, a saber: analistas judiciários/assistentes sociais; bem como verificou-se as ações e atividades requisitadas pelos magistrados aos/às profissionais pesquisadas e de que maneira tais juízes concebem o papel do Serviço Social no Tribunal de Justiça do Estado do Pará, cuja análise de conteúdo dos resultados obtidos serão sucintamente expostos nos parágrafos seguintes.

\section{Estado, Poder Judiciário e Serviço Social: Breves Apontamentos}

No âmbito das produções acadêmico-literárias do Serviço Social é bastante recorrente a discussão sobre a instituição Estado e seu papel, enquanto mediador da luta de classes, regulador da política econômica e do sistema constitucional que rege a sociedade. Configura-se um desafio descrevê-lo, compreendê-lo, interpretá-lo, pois várias são as correntes que o explicam, tanto sob uma perspectiva conservadora quanto sob uma perspectiva crítica, a partir do momento em que são confrontadas a finalidade de sua existência, sua razão de ser, com as problemáticas sociais - aqui entendidas como "questão social" - relacionadas ao conflito de classes (capitalista/burguesa x operária/trabalhadora) e 
que demandam sua intervenção enquanto agente mediador ou árbitro de todas as questões que emergem para atender aos interesses de uma dessas classes.

Dessa forma o Estado foi se complexificando à medida que a sociedade fora evoluindo e requisitando cada vez mais a intervenção dessa instituição. Assim, pode-se conceituar o mesmo como "uma sociedade politicamente organizada formada pela reunião de um povo, em um território determinado, dotado de um governo soberano" (DUTRA, 2017, p. 219), e composto por povo, território, governo, soberania e finalidade (DUTRA, 2017).

Por sua vez, Engels (1984), em sua renomada obra A Origem da Família, da Propriedade Privada e do Estado, apresenta uma argumentação teórico-filosófica sobre a origem do Estado em que expressa:

O Estado não é pois, de modo algum, um poder que se impôs à sociedade de fora para dentro; tampouco é a "realidade da idéia moral", nem a "imagem e a realidade da razão", como afirma Hegel. É antes um produto da sociedade, quando esta chega a um determinado desenvolvimento; é a confissão de que essa sociedade se enredou numa irremediável contradição com ela própria e está dividida por antagonismos irreconciliáveis que não consegue conjurar. Mas para que esses antagonismos, essas classes com interesses econômicos colidentes não se devorem e não consumam a sociedade numa luta estéril, faz-se necessário um poder colocado aparentemente por cima da sociedade, chamado a amortecer o choque e a mantê-lo dentro dos limites da "ordem". Este poder, nascido da sociedade, mas posto acima dela se distanciando cada vez mais, é o Estado (ENGELS, 1984, p. 191).

$\mathrm{Na}$ concepção desse pensador fica evidente, sob uma perspectiva históricodialética, que o Estado surgiu como uma necessidade da sociedade, quando as classes que a compunham chegaram a um nível irreconciliável acerca de seus interesses econômicos e patrimoniais referentes à propriedade privada (terras, animais, escravos, matérias-primas, instrumentos de produção etc.), consensuaram sobre o estabelecimento de uma instituição superior, porquanto, em tese, posta acima da sociedade com a incumbência de mediar os conflitos que se estabeleciam entre essas classes. O autor enfatiza, no entanto, que este Estado possui o predomínio da classe detentora do poder econômico e político para subjugar os membros da classe subalternizada por meio da "força pública", como forma de conservar o poder dessa classe dominante ao garantir a proteção da propriedade privada.

Recorrendo, de modo sintetizado, às análises sobre as teorias políticas inerentes ao Estado, Martin Carnoy (1988) desenvolve uma abordagem mais abrangente sobre tais teorias fazendo inicialmente uma análise da teoria política nos Estados Unidos, com ênfase ao pluralismo, o qual está fundamentado no princípio da liberdade individual e "reivindica 
para si o direito exclusivo da própria democracia" (CARNOY, 1988, p. 19), fundamentandose, portanto, no Estado democrático liberal, com uma versão utilitarista do papel do Estado a partir das ideias de Adam Smith. Em seguida, o autor menciona como contraponto ao pluralismo, o corporativismo social, no qual:

[...] o Estado assume um papel central no desenvolvimento capitalista e a democracia é reduzida em nome do crescimento econômico e da ordem nacional. O Estado não é visto como interferindo na eficiência de uma economia de livremercado, mas como essencial para sua racionalização" (CARNOY, 1988, p. 316, grifo do autor).

Assim, nesse sentido, o Estado, na concepção marxista, passa a apresentar uma singular conotação sob um caráter mais desfetichizado e, portanto, mais crítico e revelador. Nessa ótica, Carlos Nelson Coutinho (1989) expressa o ponto de vista marxiano, asseverando que:

\begin{abstract}
A grande descoberta de Marx e Engels no campo da teoria política foi a afirmação do caráter de classe de todo fenômeno estatal; essa descoberta os levou, em contraposição a Hegel, a "dessacralizar" o Estado, a desfetichizá-lo, mostrando como a autonomia e "superioridade" dele encontram sua gênese e explicação nas contradições imanentes da sociedade como um todo. A gênese do Estado reside na divisão da sociedade em classes, razão por que ele só existe quando e enquanto existir essa divisão (que decorre, por sua vez, das relações sociais de produção); e a função do estado é precisamente a de conservar e de reproduzir tal divisão, garantindo assim que os interesses comuns de uma classe particular se imponham como o interesse geral da sociedade (COUTINHO, 1989, p. 74, grifo do autor).
\end{abstract}

Por sua vez, a teoria neoliberal, como uma das correntes ideológicas de perspectiva político-econômica, concebe o Estado intervencionista, a exemplo do Estado de bem-estar ou Welfare State - presente nos países desenvolvidos da Europa e nos Estados Unidos e Canadá a partir do pós Segunda Guerra Mundial -, como um entrave ao desenvolvimento econômico da sociedade capitalista (LAURELL, 2002). Uma das principais propostas do neoliberalismo é o estabelecimento do chamado Estado mínimo, o qual deve se ater muito mais ao seu aspecto burocrático-funcional no âmbito de suas instituições e intervir o mínimo possível no mercado financeiro e frear ao máximo os gastos sociais para a manutenção das políticas sociais. Um dos clássicos reflexos do modelo neoliberal é a privatização dos bens e patrimônios públicos, das empresas estatais, dos serviços como telefonia, energia elétrica, água, transporte, habitação, e infraestrutura como portos e aeroportos. É o que vem ocorrendo no Brasil desde o final da década de 1980 até os dias atuais (LAURELL, 2002).

Laurell (2002, p. 162) evidencia esse contexto ao expressar que: 
Sob esse ponto de vista, a solução da crise consiste em reconstituir o mercado, a competição e o individualismo. Isto significa, por um lado, eliminar a intervenção do Estado na economia, tanto nas funções de planejamento e condução como enquanto agente econômico direto, através da privatização e desregulamentação das atividades econômicas. Por outro lado, as funções relacionadas com o bemestar social devem ser reduzidas. Usando o mesmo argumento, a competição e o individualismo só se constituiriam como forças desagregando os grupos organizados, desativando os mecanismos de negociação de seus interesses coletivos e eliminando os seus direitos adquiridos. Isto seria conseguido com a desregulamentação e flexibilização da relação trabalhista e reduzindo as normas e contribuições trabalhistas fixadas no contrato coletivo. Por último seria preciso combater o igualitarismo, pois a desigualdade é o motor da iniciativa pessoal e da competição entre os indivíduos no mercado. Apesar de todo esse antiestatismo, os neoliberais querem um Estado forte, capaz de garantir um marco legal adequado para se criarem as condições propícias à expansão do mercado.

A atual conjuntura social, política e econômica do Brasil é bem reveladora nesse sentido, especialmente com a retomada do poder de Estado por um segmento políticopartidário de cariz conservador e neoliberal que se instalou por meio de um golpe de Estado, golpe esse de caráter parlamentar-jurídico-midiático, no ano de 2016, e que levou a cabo medidas governamentais que atentam contra os direitos trabalhistas e sociais da sociedade brasileira e, como uma das características dos governos neoliberais, prioriza as políticas econômicas em detrimento das políticas sociais, o que acentua ainda mais o quadro de desigualdade socioeconômica, a precarização dos serviços públicos e as expressões da 'questão social' como o desemprego, a pobreza e a violência em suas mais diversas modalidades, manifestações estas que revelam a piora das condições de vida das classes subalternizadas.

Cabe aqui, como uma forma de avalizar as elaborações deste conteúdo, a asseveração de Behring (2008, p. 59, grifo do autor) que expressa:

No processo de enraizamento dessas novas condições, percebe-se a dissolução da unidade constitutiva do Estado e do capital nacionais. Os Estados nacionais têm dificuldades em desenvolver políticas industriais, restringindo-se a tornar os territórios mais atrativos às inversões estrangeiras. Os Estados locais convertem-se em ponto de apoio das empresas. Para Husson (1999), uma das funções econômicas do Estado - a qual Mandel caracteriza como sendo de assegurar as condições gerais de produção passou a ser a garantia dessa atratividade, a partir de novas relações entre este e grupos mundiais, onde o primeiro tem um lugar cada vez mais subordinado. Dentro disso, os Estados nacionais restringem-se a: cobrir o custo de algumas infraestruturas (sobre as quais não há interesse de investimento privado), aplicar incentivos fiscais, garantir escoamentos suficientes e institucionalizar processos de liberalização e desregulamentação, em nome da competitividade. Nesse sentido último, são decisivas as liberalizações, desregulamentações e flexibilidades no âmbito das relações de trabalho - diminuição da parte dos salários, segmentação do mercado de trabalho e diminuição das contribuições sociais para a seguridade; e do fluxo de capitais, na forma de IED e de investimentos financeiros em portfólio. Aqui tem destaque os processos de privatização, reduzindo as dimensões do setor público, para livrar-se de empresas endividadas, mas principalmente para dar "guarida" aos investidores, em especial ao IED. 
A citação textual da autora revela o quanto o Estado atua para resguardar os interesses do capital, especialmente do capital internacional, promovendo a desregulamentação e flexibilização das relações trabalhistas e desresponsabilizando-se pelos serviços públicos essenciais para atender às necessidades de sua população, em especial dos segmentos sociais subalternizados e marginalizados socialmente. O mesmo comprometeu-se com o modelo neoliberal de governar, assimilando diretrizes dos organismos multilaterais como o FMI, o BID e o Banco Mundial, os quais condicionam vultosos empréstimos bancários a elevadas taxas de juros para atender às políticas econômicas de investimentos estatais nos Estados em vias de desenvolvimento, como o Brasil, e nações de terceiro mundo que se caracterizam como colônias exportadoras de matérias-primas para atender ao mercado mundial de produtos e consumo, como muitos países asiáticos, africanos e latinoamericanos e caribenhos.

E é nesse contexto de relações sociais e econômicas na sociedade capitalista brasileira que um dos três poderes do Estado se insere de maneira ativa. Nesse aspecto, o Poder Judiciário possui a incumbência de zelar pelo cumprimento das normativas constitucionalmente celebradas nas instâncias legislativas e jurídicas e que regem o funcionamento da sociedade em geral, mediando e arbitrando conflitos de interesses, aplicando punições aos considerados culpados pela infração de leis, recomendando a implementação de ações estratégicas voltadas ao atendimento dos segmentos sociais mais desguarnecidos como idosos, crianças e adolescentes, pessoas com deficiência, mulheres vítimas de violência, dependentes químicos, encarcerados, o movimento LGBTI, grupos étnico-raciais, população ribeirinha e outros; bem como opina, orienta, regulamenta, diverge, decide e sentencia em questões de ordem política e econômica (FARIA, 2001).

A esse respeito, Bourdieu (1989), no capítulo VIII de sua grande obra O Poder Simbólico, trata da temática do campo jurídico e desde logo o considera como o espaço em que há relações de forças, concorrências, conflitos, que envolvem grupos de profissionais que procuram defender seus interesses. Tal afirmativa se respalda em um de seus conceitos, a saber:

O campo jurídico é o lugar de concorrência pelo monopólio do direito de dizer o direito, quer dizer, a boa distribuição (nomos) ou a boa ordem, na qual se defrontam agentes investidos de competência ao mesmo tempo social que consiste essencialmente na capacidade reconhecida de interpretar (de maneira mais ou menos livre ou autorizada) um corpus de textos que consagram a visão legítima, justa, do mundo social [...] (BORDIEU, 1989, p. 212) 
O espaço jurídico, concebido por Bourdieu (1989) como campo jurídico, segundo Gaglietti (2001), é um sistema organizado de atitudes vinculadas harmoniosamente aos habitus $^{1}$ de seus intérpretes, sistema esse legitimado hierarquicamente por um grupo de profissionais subordinados. São esses intérpretes (juristas) que são investidos de autoridade e de um empoderamento internalizado para executarem os veredictos e definirem a resolução dos conflitos.

Bourdieu (1989) explicita que o mencionado campo é palco de exacerbadas relações conflituosas traduzido por embates jurídicos orquestrados pelos profissionais envolvidos, os quais representam os segmentos sociais através de procuração. Sob uma leitura mais aguçada, infere-se que "é para se ver no direito e na jurisprudência um reflexo directo das relações de forças existentes, em que se exprimem as determinações econômicas e, em particular, os interesses dos dominantes" (BOURDIEU, 1989, p. 210, grifo do autor). É o chamado 'espaço dos possíveis' por se estabelecer universalmente como o lócus das soluções apresentadas juridicamente.

Segue o mesmo teórico na afirmativa que existem dois polos para a interpretação da doutrina jurídica. O primeiro diz respeito à elaboração teórica da doutrina, cuja exclusiva atribuição cabe aos professores que ensinam as formas 'normalizada' e 'formalizada' das regras vigentes. O outro polo refere-se à interpretação pragmática de um caso particular, atribuição dos magistrados que operacionalizam a jurisprudência, a qual pode se constituir objeto de estudos jurídicos e contribuir para o desenvolvimento das ações do Poder Judiciário.

Com isso, Bourdieu (1989, p. 221) resume o papel do jurista no campo jurídico ao explicitar que este:

\begin{abstract}
Participando ao mesmo tempo de um modo de pensamento teológico - pois procuram a revelação do justo na letra da lei, e do modo de pensamento lógico pois pretendem pôr em prática o método dedutivo para produzirem as aplicações da lei ao caso particular -, eles desejam criar uma "ciência nomológica" que enuncie o dever-ser cientificamente; como se quisessem reunir os dois sentidos separados da ideia de "lei natural", eles praticam uma exegese que tem por fim racionalizar o direito positivo por meio de trabalho de controle lógico necessário para garantir a coerência do corpo jurídico e para deduzir dos textos e das suas combinações consequências não previstas, preenchendo assim as famosas "lacunas do direito".
\end{abstract}

\footnotetext{
${ }^{1}$ De acordo com Gaglietti (2001, p. 84) o termo habitus "é a disposição incorporada na ação prática dos agentes sociais".
} 
O que se depreende desta afirmativa é o que muitos juristas concebem como 'jurisprudência', isto é, a assertiva jurídica que emerge para apresentar uma resolução para determinado caso quando este se apresenta não contemplado nas normativas legais vigentes, sendo necessário a interpretação do judiciário, especialmente as instâncias superiores, interpretação que servirá de referência jurídica para casos semelhantes. A jurisprudência possui caráter contemporâneo em razão de acompanhar a evolução histórica, cultural, política e social da sociedade e buscar o consenso dos grupos supramencionados: os teóricos e os pragmáticos.

Por fim, o mencionado sociólogo tece considerações sobre o veredicto, a sentença judicial, apontando-o como resultado da luta simbólica entre profissionais que detém competências técnicas e sociais distintas, os quais, de maneira desigual, operam no plano prático-científico para conquistar a vitória de uma causa que representa. Por conta disso, este mesmo veredicto "condensa toda a ambiguidade do campo jurídico" (BOURDIEU, 1989, p. 228). Com isso, quando os sujeitos optam pela ação do direito, optam tacitamente por um tipo de expressão e discussão que abdica da violência física e da violência simbólica (p. ex.: injúria). Logo, o autor assegura que o campo jurídico, em relação às demais instituições dos demais poderes estatais, é o que possui o menor nível de autonomia.

Em sequência, Faria (2001, p. 8) expressa uma das funções do Poder Judiciário:

[...] ele foi concebido para, no exercício dessas funções, preservar a propriedade privada, conferir eficácia aos direitos individuais, assegurar os direitos fundamentais, garantir as liberdades públicas e afirmar o império da lei, protegendo os cidadãos contra os abusos de poder do Estado. [...] o Poder Judiciário também passou a implementar direitos sociais, condicionando a formulação e execução de políticas públicas com propósitos compensatórios e distributivistas.

O Poder Judiciário no Brasil apresenta históricas limitações que afetam sua organicidade, eficiência e eficácia, e que são expressas pelo acúmulo exacerbado de processos judiciais e por outros aspectos em que se acusam a existência e implementação de sentenças dúbias, seu caráter funcional-corporativista e a ausência de imparcialidade em muitos de seus veredictos. Um desses fatores é explicitado por Alapanian Colmán (2004, p. 334) quando assevera que:

[...] o Poder Judiciário brasileiro - que diferentemente do Judiciário de países como os Estados Unidos, não nasceu de um processo de independência nacional, mas de uma adaptação e acomodação dos quadros do Judiciário do período colonial -, esteve sempre subordinado aos interesses do Executivo, não obtendo nem sequer força suficiente para funcionar como elemento independente dentro da lógica liberal da divisão de poderes no interior do Estado. 
Nesse sentido, observa-se que, estrutural e oficialmente no Brasil, este poder está representado pelos seguintes órgãos: Supremo Tribunal Federal (STF); Superior Tribunal de Justiça (STJ); Tribunal Regional Federal (TRF); Tribunal Regional do Trabalho (TRT); Tribunal Superior Eleitoral (TSE); Tribunal Regional Eleitoral (TRE); incluem-se ainda os tribunais militares e tribunais de justiça dos estados e do Distrito Federal. Consequentemente, estes órgãos tratam de temas relacionados às questões civis, penais, eleitorais, trabalhistas e militares. Em seus aspectos organizacionais, Faria (2001, p. 9) assevera que "o Poder Judiciário foi estruturado para operar sob a égide dos códigos processuais civil, penal e trabalhista". Aqui implica a metodologia de atuação do sistema jurídico nos tribunais e que envolvem magistrados, promotores, defensores públicos, advogados e auxiliares da justiça concebidos como peritos - profissionais de nível superior, dentre os quais está o(a) assistente social.

Por sua vez, ao referir-se sobre a atuação do Serviço Social no campo sociojurídico, registra-se que esta profissão se insere nas instituições do Poder Judiciário no final da década de 1940 em São Paulo, inicialmente como voluntários no Juizado de Menores para lidar com 'problemas sociais' relacionados aos 'desajustes' sociais de menores de 18 anos, bem como de famílias 'desestruturadas', cujos aspectos comportamentais eram encarados como 'casos de polícia'. Tal inserção fora assegurada pela Lei no 560, de 27 de dezembro de 1949, que instituiu o Serviço de Colocação Familiar no Estado de São Paulo. As ações, nesse sentido, estavam voltadas ao controle e à manutenção da ordem social, denotando-se desde essa época que a pobreza já era criminalizada (FÁVERO; MELÃO; JORGE, 2005).

Confluindo nesse mesmo contexto, Silvia Alapanian Colmán (2004) ilustra o caráter da inserção do Serviço Social no Poder Judiciário e sua evolução enquanto profissão interventiva ao afirmar que:

\footnotetext{
Articulados politicamente com o Judiciário através da democracia cristã e presentes no interior da organização judiciária desde 1949 quando se deu início à criação da estrutura assistencial no interior do Juizado de Menores, os assistentes sociais mostraram-se profissionais competentes para criar e administrar tais serviços. A qualificação dos seus quadros e a utilização de parâmetros técnicos profissionais por parte dos assistentes sociais foram importantes para dar aos serviços que estavam sendo criados a característica de seriedade e o profissionalismo que o Judiciário buscava demonstrar na tentativa de se diferenciar do Poder Executivo, na época, e se credenciar como ator na definição de políticas públicas, como parte de um plano mais geral de demonstração de força e independência (ALAPANIAN COLMÁN, 2004, p. 339).
} 
É válido ressaltar, que o chamado campo ou área sociojurídica não se restringe ao Poder Judiciário, vai além dele e permeia outros espaços sócio-ocupacionais relacionados ao sistema judiciário, conforme afirma Fávero (2003) ao expor que:

Campo (ou sistema) sociojurídico diz respeito ao conjunto de áreas em que a ação social do Serviço Social articula-se a ações de natureza jurídica, como o sistema penitenciário, o sistema de segurança, os sistemas de proteção e acolhimento, como abrigos, internatos, conselhos de direitos, dentre outros (FÁVERO, 2003, p. 10).

Embora a citação acima tenha apresentado um conceito a respeito desse campo, sistema ou área sociojurídica com o elenco de alguns espaços em que a intervenção técnica do/a assistente social é efetivada, essa definição não está consolidada, pois não se observou, por exemplo, referência ao Ministério Público, à Defensoria Pública e ao Conselho Tutelar, os quais não podem compor o termo "dentre outros" dada sua importância no mencionado campo. Isso implica em considerar que a discussão sobre as instituições, órgãos, entidades e movimentos, cujas ações e atividades estão relacionadas sociojuridicamente, ainda se apresenta como um processo em construção no que tange à classificação enquanto componentes desse mesmo campo.

Destarte, mencione-se também as legislações infraconstitucionais relativas aos segmentos sociais que demandam por políticas de proteção e atendimento de suas peculiares necessidades, a exemplo das crianças e adolescentes, mulheres vítimas de violência e pessoas idosas, que obrigaram o Poder Judiciário a criar e instalar varas especializadas e destinadas a atender esses segmentos. O elemento motriz para essa conjuntura social e política foi a promulgação da Constituição Federal de 1988, a qual propiciou o reconhecimento, o fortalecimento e a regulamentação via políticas públicas dos direitos de cidadania, bem como fortalecera também o papel do Poder Judiciário enquanto guardião da referida Carta Magna e, portanto, em tese, da democracia, da justiça e da liberdade. Consequentemente, nesse processo, o Serviço Social passou a ser amplamente requisitado, o que ampliou seu mercado de trabalho (ALAPANIAN COLMÁN, 2004).

Paralelamente a isso, pode-se inferir que o Serviço Social no campo sociojurídico passou a adquirir notoriedade no âmbito dos debates teórico-metodológicos e técnicooperativos a partir de sua exposição na Revista Serviço Social \& Sociedade, no 67, de setembro de 2001, e que trouxe inclusive um neologismo para a profissão com a adoção do termo sociojurídico, o qual passou a ser utilizado nos posteriores espaços de debates sobre a 
temática do campo jurídico, principalmente a partir do X Congresso Brasileiro de Assistentes Sociais (CBAS), também em 2001.

Consequentemente foi produzida pelo CFESS a publicação O Estudo Social em Perícias, Laudos e Pareceres Técnicos: contribuição ao debate no Judiciário, Penitenciário e na Previdência Social, no ano de 2003. Em sequência, no de 2004 e por deliberação do XXXII Encontro Nacional CFESS/CRESS (CONSELHO FEDERAL DE SERVIÇO SOCIAL, 2003), realizou-se em Curitiba-PR o I Seminário Nacional do Serviço Social no Campo Sociojurídico. Em 2009, na cidade de Cuiabá-MT, fora realizado o II Seminário Nacional: o Serviço Social no Campo Sociojurídico na Perspectiva da Concretização de Direitos.

Tais debates do Serviço Social no campo sociojurídico enfatizaram, dentre outros fatores, que a dinamicidade desse campo de intervenção passou a requisitar cada vez mais a atuação do/a assistente social em razão das novas demandas sociojurídicas que se apresentaram conectadas à legitimação e legalização de 'novos' direitos civis e sociais, especialmente ligados às necessidades sociopolíticas de segmentos populacionais como as pessoas com deficiência, idosos, crianças e adolescentes, mulheres vítimas de violência, imigrantes e refugiados, pessoas em situação de rua, dependentes químicos, pessoas em situação de cárcere institucional, LGBTI, trabalhadores rurais sem terras, indígenas, ribeirinhos, quilombolas, trabalhadores em situação análoga ao trabalho escravo, e famílias pauperizadas e marginalizadas socialmente.

\section{O Serviço Social no Poder Judiciário Paraense: a Consolidação de Seu Papel na Comarca de Marabá}

O Serviço Social no Estado do Pará se constituía uma profissão nova, cuja implantação remonta a década de 1950, a partir da iniciativa do Sr. Paulo Eleutério Sênior, ligado ao SESI, o qual, dentre outras formações acadêmicas, era jornalista e cientista social, e fundou a escola de Serviço Social no Pará, no ano de 1950. A chegada da profissão no Pará originou-se pela busca de modernização da gestão da força de trabalho (NETTO,1992), ligado aos interesses do empresariado local. A primeira turma de Serviço Social formada por esta escola data de 1958. Em 1963, o curso fora encampado pela Universidade Federal do Pará por força da Lei no 4.283/63 (SANTOS NETO, 2017). 
Por sua vez, no âmbito do Poder Judiciário, a presença de assistente social no quadro de servidores do TJE/PA decorre do Código Judiciário paraense de $1972^{2}$, o qual registrou a criação do cargo de assistente social para atuar no Juizado de Menores. No entanto, não se localizou, no período de 1973 a 1980, registro no TJE/PA, precisamente na Secretaria de Gestão de Pessoas - SGP, de assistente(s) social(is) contratado/a(s) para atuar nesse órgão. Por outro lado, de acordo com informações obtidas junto à assistente social aposentada da mencionada instituição judiciária, Sr. ${ }^{a}$ Nazaré Mendonça, a primeira assistente social dessa instituição denominava-se Marlene. Posteriormente, mediante solicitação encaminhada à SGP do referido órgão judiciário, constatou-se que a Sr. a Marlene Ribeiro Coutinho, fora aprovada em processo seletivo interno e ingressou na instituição por meio de decreto datado de 19.12.1980, assumindo o cargo de assistente social a partir de 01.01.1981, o que representa efetivamente o marco da inserção do Serviço Social no Poder Judiciário paraense.

No que tange ao município de Marabá, informe-se que o mesmo se localiza na região Sudeste do estado do Pará, há cerca de 540 km de distância da capital, Belém-PA, e foi fundado no dia 05 de abril de 1913. Segundo dados e informações do Instituto Brasileiro de Geografia e Estatísticas - IBGE (2018), sua área geográfica territorial é de 15.128,058 km²; possui uma população estimada no ano de 2017 em 271.594 habitantes; seu índice de desenvolvimento humano - IDH é de 0,668 (2010). Possui o 3.o maior produto interno bruto - PIB do estado com valor em 2017 equivalente a R\$ 7.326.872.000,00 (sete bilhões, trezentos e vinte e seis milhões, oitocentos e setenta dois mil reais) e renda per capta de $\mathrm{R} \$$ 27.956,09 (vinte e sete mil, novecentos e cinquenta e seis reais e nove centavos).

A composição financeiro-econômica municipal se pauta na produção agropecuária e mineral, além de recursos advindos do funcionalismo público das três esferas administrativas (União, estados e municípios), do setor de comércio e serviços, da previdência social (benefícios previdenciários e 'assistencial' como o BPC), dos programas sociais de transferência de renda mínima (programas da política de assistência social como o Bolsa Família), do Fundo de Participação dos Municípios - FPM, da arrecadação pública, de royalties de mineradoras como a empresa Vale e dos repasses de recursos do Governo Federal, repasses estes cujo montante no ano de 2017 foi equivalente a $R \$ 357.529 .185,61$

\footnotetext{
2 Por meio de pesquisa documental, fora localizado um exemplar digitalizado do Código Judiciário de 1972 na página virtual do TJE/PA (PARÁ, 1972).
} 
(trezentos e cinquenta e sete milhões, quinhentos e vinte e nove mil, cento e oitenta e cinco reais, e noventa e três centavos) $)^{3}$.

A respeito da inserção de assistentes sociais na comarca judiciária em questão, obteve-se a informação por meio de pesquisa documental e de relato de servidores da Secretaria do Fórum da Comarca de Marabá a indicação do nome da Sr.a Sandra Maria dos Santos Medeiros, servidora da antiga FBESP (Fundação de Bem-Estar Social do Pará), atual FASEPA (Fundação de Atendimento Socioeducativo do Pará) e lotada nesta última, como a primeira assistente social a atuar nesse referido espaço sócio-ocupacional em caráter de cessão interinstitucional, cuja atividade se iniciou no dia 21 de setembro de 1993 e findou em 10 de outubro de 1999; todavia, a mesma foi acionada para acompanhar processos das varas cíveis no período de 20.03.2000 a 24.05.2007.

A pesquisa documental efetuada e os relatos advindos de servidores da mencionada secretaria evidenciou ainda que o primeiro assistente social do quadro de servidores efetivos do TJE/PA a ser lotado na Comarca de Marabá foi o analista judiciário/assistente social, Sr. Edevaldo da Luz Azevedo, o qual foi nomeado em 16 de janeiro de 2007 por meio da Portaria no 0132/2007, entrando em efetivo exercício no dia 05 de fevereiro de 2007, exercendo sua funções até os dias atuais.

Atualmente os/as assistentes sociais, analistas judiciários da Comarca de Marabá, componentes do quadro de servidores efetivos do TJE/PA, totalizam 09 profissionais, dentre os quais 06 estão lotados na sede da referida comarca - município de Marabá, 02 lotadas em Parauapebas e 01 em Tucuruí. Todos estes profissionais atuam em varas cíveis e de execução penal, e atuam em processos jurídicos relativos à guarda, tutela, adoção, curatela; suspensão e destituição do poder familiar, pensão alimentícia, indicação de aplicação de medida socioeducativa a adolescentes em conflito com a lei; acompanhamento em casos de busca e apreensão de criança e/ou adolescente; acolhimento e desacolhimento institucional de crianças e adolescentes vítimas de abandono, negligência e maus tratos; indicação de aplicação de penas alternativas e acompanhamento de execuções penais, e outras ações e atividades aqui concebidas como demandas sociojurídicas.

No processo de pesquisa de campo, as evidências empíricas demonstraram que, concernente à categoria da prática profissional e da utilização dos instrumentais e técnicas como prerrogativa das assistentes sociais para efetivar as perícias sociais, a exposição sobre

\footnotetext{
${ }^{3}$ Dados obtidos no Portal da Transparência do Governo Federal. (BRASIL, 2017).
} 
o exercício de um estudo preliminar sobre o teor das demandas sociojurídicas singulares com os quais as profissionais trabalharão se apresentou como uma atividade da prática profissional na instituição judiciária. Com isso, planeja-se intervenção técnica, em caráter individual ou enquanto membro de equipe interdisciplinar, e parte-se, então, para a utilização dos instrumentais técnicos como visita domiciliar e/ou institucional, entrevista e observação. Após, procede-se ao registro dos dados e informações, obtidos no citado processo técnico-operativo, em laudo técnico e emite-se um parecer que deve necessariamente apresentar a opinião técnica do/a profissional sobre o objeto trabalhado.

As assistentes sociais pesquisadas observaram em suas verbalizações, na relação com seus sujeitos de atendimento, a necessidade de utilização de técnicas como a linguagem apropriada para ser adequadamente apreendida, compreendida e interpretada por seus citados interlocutores numa relação intersubjetiva. Outra categoria explicitada pelas próprias é o acolhimento, o qual requisita uma conduta profissional com atenção e cordialidade; e associada a esta última fora mencionada também a escuta, relacionada à atenção com interesse, compreensão e disposição para resolver ou encaminhar para as devidas providências resolutivas as questões e demandas que seus sujeitos de atendimento Ihes apresentam (LAVORATTI; COSTA, 2016).

Já para os magistrados, a prática profissional das assistentes sociais da e na Comarca de Marabá se resume na elaboração de estudos sociais com vistas a subsidiar as decisões judiciais, distinguindo-se por sua postura mais 'humanista' no trato das citadas demandas. Os magistrados, também sujeitos da pesquisa realizada, não elencaram outras ações e atividades desenvolvidas pelas profissionais, a exemplo daquelas assinaladas acima, restringindo-se a enfatizar apenas o objeto de suas requisições às referidas trabalhadoras. Dessa forma, os mesmos demonstraram, com isso, uma limitada apropriação conceitual, ainda que restrita à dimensão técnico-operativa, a respeito do papel do Serviço Social no campo sociojurídico.

Referente ao objetivo correspondente à percepção das condições de trabalho das profissionais informantes da pesquisa, pode-se identificar, de uma maneira geral, que as condições de trabalho são adequadas e relativamente dignas, inobstante as assistentes sociais terem apontado a ausência e indisponibilidade de uma sala para atendimento privativo das pessoas que demandam seus serviços, atendimento este que frequentemente ocorre por meio de entrevistas e exige sigilo profissional. Nesse sentido, para contornar a 
citada indisponibilidade de espaço para tal atendimento, algumas adequações improvisadas são necessárias para garantir este atendimento com o requerido sigilo.

Outro fator citado como condição adequada para o desenvolvimento da prática profissional no âmbito da Comarca de Marabá concerne à disponibilidade de veículo com motorista para a efetivação das visitas domiciliares e institucionais, pois, apesar de disporem desse instrumento e do profissional correspondente, isso ocorre de modo limitado em razão de adequação aplicada pela direção do Fórum da Comarca de Marabá, e que afeta a celeridade do fluxo dos processos judiciais como um todo.

Relacionado às condições éticas de trabalho, a categoria correspondente ao relacionamento interprofissional que envolve as assistentes sociais sujeitos da pesquisa e os demais profissionais e servidores desse espaço judiciário, revelou, pela fala das informantes, não haver a ocorrência de tensões e conflitos nesse ambiente de trabalho, e muito menos episódios de assédio moral. Apenas uma das pesquisadas revelou ter ocorrido certo desentendimento desta com magistrado e diretor de secretaria, mas que paulatinamente essa situação foi superada. As profissionais revelaram uma relação mais difícil com juízes substitutos de suas respectivas varas de atuação, em função de que estes ora não priorizavam as demandas sociojurídicas ora requisitavam com bastante frequência a elaboração de estudos sociais no afã de se atingir um quantitativo de metas judiciárias, sem interagir adequadamente com as profissionais para que as citadas demandas fossem devidamente encaminhadas de maneira resolutiva.

Nesse aspecto, pertinente ao relacionamento interprofissional no ambiente de trabalho, observou-se nas falas dos sujeitos pesquisados uma preocupação por expressões mais cautelosas quando referentes a outros profissionais, especialmente em relação aos magistrados, em que se enfatizou os aspectos positivos no ambiente de trabalho, sem se mencionar as diferenças de enfoque e de concepções teóricas e metodológicas de outros profissionais no que concerne ao trato de determinadas demandas, sobre os objetivos que repousam em cada intervenção técnica, em cada requisição judicial, ou seja, se o chamado "olhar" desse outro profissional se apresenta como legalista, com leitura conservadora da realidade social ou se esse mesmo "olhar" coaduna com os parâmetros ético-políticos e teórico-metodológicos do Serviço Social.

Finalmente, as declarações dos magistrados emergiram sob a denotação do reconhecimento positivo do papel desempenhado pelas trabalhadoras do Serviço Social, as 
quais foram consideradas de fundamental importância para a movimentação dos trabalhos jurídicos, em razão de que a atribuição do Poder Judiciário não se restringe ao processo judicial em si com suas implicações processuais de trâmite e perícias. Logo, a verbalização dos magistrados pesquisados procura genérica e diplomaticamente revelar a relevância do teor técnico-operativo das competências e atribuições das profissionais, limitando-se aos seus aspectos funcionais na instituição sem mencionar, por outro lado, as demais ações e atividades que as mesmas realizam para além de seu espaço sócio-ocupacional.

Nessa trajetória, a pesquisa revelou o caráter imprescindível das ações e atividades desenvolvidas pelas analistas judiciárias/Serviço Social do TJE/PA no âmbito da Comarca de Marabá. Ademais, infere-se, em razão das peculiaridades geográficas que se resvalam nos aspectos sociais, culturais, políticos e econômicos dessa região lócus da pesquisa, que a reprodução das relações sociais adquire uma forma peculiar, ainda que haja uma verticalização das diretrizes no trato das sequelas da 'questão social' no campo da política de assistência social com quem o Poder Judiciário estabelece uma interface, para lidar com os objetos demandados no cotidiano das ações interinstitucionais por meio das políticas públicas nesse recanto do interior da Amazônia.

\section{Conclusões}

Como se pode averiguar, são múltiplas as demandas sociais para se atender aos diversos públicos-alvo. Salienta-se ainda, que o profissional de Serviço Social, no âmbito jurídico, não atende exclusivamente as pessoas e grupos desprovidos dos mínimos sociais ou de baixa renda, e sim também pessoas e famílias de elevado poder aquisitivo que compõem o grupo da chamada "classe média" brasileira. Um grande exemplo disso são os processos judiciais de guarda, tutela, curatela e adoção das varas de Família e Sucessões e da Vara da Infância e Juventude, cujos requerimentos são oriundos de diversos grupos familiares dos variados níveis socioeconômicos.

É nessa realidade que as assistentes sociais pesquisadas implementam seu agir profissional em um ambiente que expressa conflitos, relações de poder, correlações de força, desigualdade e até injustiças, desenvolvendo suas ações e atividades enquanto peritas, auxiliares, assessoras e componentes de equipe interdisciplinar, buscando compreender sua singularidade e estabelecer os nexos causais pela abstração de suas categorias determinantes para, intencional e teleologicamente, apreender as determinações 
que envolvem as demandas sociojurídicas, as quais estão diretamente vinculadas às expressões da questão social. Esse processo inerente ao exercício profissional requer o perfil de um/uma assistente social crítico/a, competente nas múltiplas dimensões da prática profissional e compromissado com as classes subalternizadas (IAMAMOTO, 2011).

Essa modalidade de apreensão racional-cognitiva do real se expressa em suas intervenções técnico-operativas, as quais se consolidam na efetivação de perícias sociais e na concretude de estudos sociais, relatórios, laudos e pareceres, todos substancialmente elaborados e que possibilitam a fundamentação, geralmente inconteste, de decisões judiciais com ou não resolução do mérito, e que asseguram ao(s) sujeito(s) alvo(s) de suas intervenções profissionais à possibilidade de acessar determinados direitos de cidadania que são legitimados tanto legal, quanto jurisprudencialmente pelo Poder Judiciário. Portanto, aqui nesse peculiar campo de atuação, o Serviço Social operacionaliza o direito e firma-se como profissão que busca exercer sua prática em consonância com os princípios e valores éticos, cujo conjunto de ações buscam convergir para a consolidação de seu projeto éticopolítico na perspectiva de uma sociedade republicana justa, democrática, segura e igualitária.

\section{Referências}

ALAPANIAN COLMÁN, S. A formação do serviço social no poder judiciário: reflexões sobre o direito, o poder judiciário e a intervenção do serviço social no Tribunal de Justiça do Estado de São Paulo 1948-1988. 2004. 355 f. Tese (Doutorado em Serviço Social) - Pontifícia Universidade Católica de São Paulo, São Paulo, 2004.

BARDIN, L. Análise de conteúdo. São Paulo: Ed. 70, 2011.

BEHRING, Elaine Rossetti. Brasil em Contra-Reforma: desestruturação do Estado e perda de direitos. 2. ed. São Paulo: Cortez, 2008.

BOURDIEU, Pierre. O poder simbólico. Lisboa: Difel, 1989.

BRASIL. Ministério da Transparência e Controladoria-Geral da União. Portal da Transparência. Transferência de Recursos por Estado/Município: UF: PA, Município: Marabá Exercício: 2017. Brasília, 2017. Disponível em:

<http://www.portaltransparencia.gov.br/localidades/1504208-maraba?ano=2017] $>$. Acesso em: 17 abr. 2018.

CARNOY, M. Estado e teoria política. 2. ed. Campinas: Papirus, 1988. 
CONSELHO FEDERAL DE SERVIÇO SOCIAL. O estudo social em perícias, laudos e pareceres técnicos: contribuição ao debate no Judiciário, Penitenciário e na Previdência Social. São Paulo: Cortez, 2003.

COUTINHO, C. N. Gramsci: um estudo sobre seu pensamento político. Rio de Janeiro: Campus, 1989.

DUTRA, L. Direito constitucional essencial. 3. ed. Rio de Janeiro: Forense; São Paulo: Método, 2017.

ENGELS, F. A origem da família, da propriedade privada e do estado.9. ed. Rio de Janeiro: Civilização Brasileira, 1984.

FARIA, J. E. O poder judiciário nos universos jurídico e social: esboço para uma discussão da política judicial comparada. Serviço Social \& Sociedade, São Paulo, v. 22, n. 67, set. 2001.

FÁVERO, E. T. O estudo social: fundamentos e particularidades de sua construção na Área Judiciária. In: CFESS (Org.). O estudo social em perícias, laudos e pareceres técnicos: contribuições ao debate no judiciário, penitenciário e na previdência social. São Paulo: Cortez, 2003.

FÁVERO, E. T.; MELÃO, M. J. R.; JORGE, M. R. T. O serviço social e a psicologia no judiciário: construindo saberes, conquistando direitos. 2. ed. São Paulo: Cortez, 2005.

GAGLIETTI, M. O discurso jurídico como articulador da "sociedade". Serviço Social \& Sociedade, São Paulo, v.22, n. 67, p. 83-91, set. 2001.

IAMAMOTO, M. V. Serviço social em tempo de capital fetiche: capital financeiro, trabalho e questão social. 5. ed. São Paulo: Cortez, 2011.

IBGE - Instituto Brasileiro de Geografia e Estatísticas. Marabá-PA: panorama. Disponível em: <http://cidades.ibge.gov.br/brasil/pa/maraba/ panorama>. Acesso em: 17 abr. 2018.

LAURELL, A. C. Estado e políticas sociais no neoliberalismo. 3. ed. São Paulo: Cortez, 2002.

LAVORATTI, Cleide; COSTA, Dorival (Org.). Instrumentos técnico-operativos no serviço social: um debate necessário. Ponta Grossa: Estúdio Texto, 2016.

NETTO, J. P. Capitalismo monopolista e serviço social. São Paulo: Cortez, 1992.

PARÁ. Tribunal de Justiça. Código Judiciário: resolução № 7. Belém, 1972. Disponível em: <http://www.tjpa.jus.br/CMSPortal/VisualizarArquivo?idArquivo=11150>. Acesso em: 15 abr. 2018.

SANTOS NETO, F. A institucionalização do serviço social no Pará: uma profissão inscrita na Amazônia. In: JORNADA INTERNACIONAL DE POLÍTICAS PÚBLICAS, 8., 2017, São Luís. Anais... São Luís: Universidade Federal do Maranhão, 2017. 